corporation into farm practice. Each farmer should interpret experimental results for himself and try to relate them to his own specific conditions. He should try new methods which, in the light of his experience, offer advantages. The trial may fail, but it is far better to fail on the chance of succeeding than not to try out a new technique simply because in trial plots the results did not attain the desired level of significance to suit the statisticians.

Future prospects are very ably summarized in a final chapter when problems facing both research workers and farmers are clearly stated. The problems cited do not simply concern grass as a crop, but also the animals which consume the grass. Animal nutrition is as important as crop nutrition, and only of recent years has research indicated that there are fundamental differences in herbage plants which dictate the reactions of animals to them in the digestibility and production secured from them when eaten by ruminants. Parasitism raises a multitude of fresh problems which indicates the need for team work between physiologists, veterinarians and agronomists. Then, too, the underground parts of the grass plant are frequently as important, if not more so, than the aerial ones.

Since the first edition of this book appeared in 1952, our knowledge of the grass crop has greatly increased and the full appreciation of its vital role in British agriculture is now more widely acknowledged. The author incorporates throughout the text recent results from experiments at the Grassland Research Institute for Great Britain as well as from elsewhere.

All students of agriculture at all levels should make a point of not only reading this book carefully, but also of studying it seriously. An excellent bibliography and a serviceable index add greatly to its value for students. It has in my view, however, a wider value, and biologists, geographers, geologists and indeed all interested in the countryside will find profit and fascination in its pages.

IAN MOORE

\section{CRYSTAL GAZING}

\section{Computing Methods and the Phase Problem in $X$-ray Crystal Analysis}

Report of a Conference held at Glasgow, August, 1960. Edited by Ray Pepinsky, J. M. Robertson, and J. C. Speakman. (International Tracts in Computer Science and Technology and their Application, Vol. 4). Pp. viii +326 . (London and New York: Pergamon Press, 1961.) 63s. net.

\section{Crystal-structure Analysis}

By Prof. Martin J. Buerger. Pp. xvii +668. (New York : John Wiley and Sons, Ine.; London: John Wiley and Sons, Ltd., 1950.) 18.50 dollars; $148 s$.

A BOUT a decade ago there was held at Pennsylvania State College a conference on "Computing Methods and the Phase Problem in X-ray Crystal Analysis". The main purpose of this meeting was to exhibit the new X-RAC computer designed by Ray Pepinsky, and the volume which described the conference and the machine is one of the important landmarks in the literature of the subject.

Of the machine itself little need be said except that it forms the most powerful tool for Fourier synthesis which has so far boen produced. The other papers in the earlier volume were chiefly concerned with the central problem of X-ray analysis, the determination of phase.

In the new book under review, we see how the hopes and aspirations of the workers have developed. The $\mathrm{X}-R A C$ is still the most powerful machine for its special purpose, but, as Pepinsky points out, it is "an anomaly among computers", an analogue machine which is more economical and capable of greater accuracy for its special purposes than any digital machine yet on the market. Neverthelass, the machine will become of less importance in the future because of the development of new techniques and of the essentially versatile nature of digital machines.

The main portion of the book is, however, concerned with two aspects of modern structure analysis: digital computation and phase determination. Of the former it may be said that all the principal machines and programmes are described. The papers vary from the mere catalogue of programmes for an $I B M$ ' 650 ', provided by Jeffrey and Shiono, to the extensive description of Pegasus and its programmes given by Cruikshank. To say that these papers were dull would be unfair, but they are unlikely to be of great interest to anyone who does not have access to one of the machines described. An exception should perhaps be made in favour of Robertson's paper, which describes a charming little machine having the code-name Rufus, an indication that in these days of high-speed electronics there is still place for mechanical ingenuity.

The papers which deal with phase determination and theoretical crystallography are revealing. They range from the extremely useful analysis of leastsquares techniques by Sparks, to the disappointingly short paper on the later history of direct methods of phase determination by Hauptman. Experimental methods of phase determination also receive attention and the phase part of the book may be summed up by the statement that, with complex structures at least, if no experimental method of phase determination is available the theoretical methods are unlikgly to be of much help.

Thy book is well produced, and authors, editors and publishers alike must be congratulated on producing it so soon after the conference. It will be an essential book for all serious crystallographers.

Buerger's book, while dealing with many of the topics covered by the specialists in the previous work, is a systematic study of the whole process of crystal structure analysis. It starts with a description of the fundamental processing of X-ray diffraction, explains the experimental techniques which are used to obtain X-ray data, and then derives the various expressions which are needed to reduce these data to a form suitable for Fourier analysis.

The latter part of the book is a compendium of Fourier methods, from practical procedures of computation to theoretical techniques of phase determination. Although the book contains nearly 700 pages the whole subject of vector space is barely mentioned-it is the subject of an earlier book by Buerger - and one gets the impression of increasing compression of treatment towards the end. This terseness is, however, relieved by the excellent lists of references which end each chapter, and, were it not for the extremely high price, every student of crystallography would find the book an essential part of his library.
A. D. Воотн 